\title{
Growth of lead molybdate crystals by vertical Bridgman method
}

\author{
HONGBING CHEN*, CONGXIN GE, RONGSHENG LI, JINHAO WANG, \\ CHANGGEN WU ${ }^{\dagger}$ and XIANLING ZENG ${ }^{\dagger}$
}

Municipal Key Laboratory of Inorganic Materials, Institute of Solid State Chemistry, Ningbo University, Ningbo 315211 , P.R. China

${ }^{\dagger}$ Department of Materials Science, University of Science and Technology of China, Hefei 230026, P.R. China

MS received 14 February 2005

\begin{abstract}
The growth of $\mathrm{PbMoO}_{4}$ crystals by the modified Bridgman method has been reported in this paper. The feed material with strict stoichiometric composition is desirable for the Bridgman growth of the crystals. The continuous composition change of the melts during growth can be avoided because the volatilization of melts is limited by sealed platinum crucibles. By means of the optimum growth parameters such as the growth rate of $<1.2 \mathrm{~mm} / \mathrm{h}$ and the temperature gradient of $20 \sim 40^{\circ} \mathrm{C} / \mathrm{cm}$ across the solid-liquid interface under the furnace temperature of $1140 \sim 1200^{\circ} \mathrm{C}$, large size crystals with high optical uniformity were grown successfully. The distribution of $\mathrm{Pb}$ and Mo concentration along the growth axis was measured by $\mathrm{X}$-ray fluorescence analysis. The single crystallinity of the grown sample was evaluated by the double-crystal $X$-ray rocking curve. The transmission spectra were measured in the range of $300-800 \mathrm{~nm}$ at room temperature.
\end{abstract}

Keywords. Crystal growth; Bridgman method; acousto-optic crystal; lead molybdate.

\section{Introduction}

Lead molybdate $\left(\mathrm{PbMoO}_{4}, \mathrm{PMO}\right)$ crystal is well known as an acousto-optic material with excellent properties such as higher acoustic-optic figure of merit and lower acoustic loss (Pinnow 1969). The crystal has attracted much interest for its application in acousto-optic modulators, deflectors and filters. The phase diagram of $\mathrm{PbO}-$ $\mathrm{MoO}_{3}$ system (Jaeger et al 1921) shows that PMO crystal can be melted congruently with $50 \mathrm{~mol} \% \mathrm{PbO}$ at $1065^{\circ} \mathrm{C}$. Efforts have been made to grow large-sized crystals of high quality for applications in acoustic-optic devices. In the previous studies, most of the investigations were focused on the conventional Czochralski process, in which the crystals were pulled from the melts with congruent composition (Bonner and Zydzik 1970; Takano 1974; He et al 1980; Lim et al 1996; Senguttuvan et al 1997a,b; Zeng 1997). Almost all commercially available PMO crystals are grown by Czochralski process. The main difficulties in Czochralski growth of crystals are (i) continuous composition change of melts during growth because of serious volatilization of $\mathrm{PbO}$ and $\mathrm{MoO}_{3}$ and (ii) cracking in as-grown crystals due to the anisotropy of thermal expansion. Considering that PMO crystal is a congruently melted compound with a moderate temperature, an alternative method, Bridgman method is a promising technique to overcome the difficulties in Czochralski growth. The modified vertical Bridgman process was

*Author for correspondence (chenhongbing@ nbu.edu.cn) used to grow large sized PMO crystals in our laboratory. In this paper, we present what is to our knowledge the first report on the vertical Bridgman growth of PMO crystals, which is demonstrated to be an advantageous process for mass growth of PMO crystals.

\section{Experimental}

The feed material for PMO crystal growth was synthesized from the high purity, $\mathrm{PbO}(99.99 \%)$ and $\mathrm{MoO}_{3}$ (99.99\%), according to the chemical stoichiometry. The starting agents were sintered at $200^{\circ} \mathrm{C}$ for $3 \mathrm{~h}$ to remove the moisture. The agents were mixed for $3 \mathrm{~h}$ in a nylon ball mill and filled in a platinum crucible. The mixture was sintered at the temperature of $900 \sim 950^{\circ} \mathrm{C}$ for $1 \mathrm{~h}$ and then at $1100^{\circ} \mathrm{C}$ for $0.5 \mathrm{~h}$ so that the compound, $\mathrm{PMO}$, was synthesized and homogenized by the solid phase reaction. The feed material obtained was identified to be PMO phase by X-ray powder diffraction and DTA analysis. The dense polycrystalline charge without moisture allowed more efficient filling of the crucibles in the following process. As a comparison, the feed material was alternatively synthesized from the high purity $\mathrm{Pb}\left(\mathrm{NO}_{3}\right)_{2}$ $(99.99 \%)$ and $\left(\mathrm{NH}_{4}\right)_{2} \mathrm{MoO}_{4}(99.99 \%)$ by the precipitating reaction in aqueous solution. The two agents with the molar ratio $1: 1$ were dissolved to be saturated solutions and precipitation occurred as the two solutions mixed together by stirring. The feed material with accurate stoichiometry was obtained after the precipitation was filtered and dried. 
PMO crystal was grown by a resistively heated vertical Bridgman furnace as shown in figure 1. The furnace temperature was adjusted by a WJK-100 A fine temperature controller with an accuracy of $\pm 0.5^{\circ} \mathrm{C}$ during the experiments. Figure 2 shows the axial temperature distribution in the furnace. According to the axial temperature distribution, the furnace chamber can be divided into three zones, i.e. the high-temperature zone, the gradient zone and the low-temperature zone. During the crystal growth, the melt was homogenized in the crucibles in the high-temperature zone, while the grown crystal could be annealed in the low-temperature zone. The solid-liquid interface was located in the gradient zone. The high-temperature zone was usually controlled at $1140 \sim 1200^{\circ} \mathrm{C}$, which was about $75 \sim 135^{\circ} \mathrm{C}$ higher than the melting point of crystal. The horizontal temperature distribution was kept as uniform as possible. In this work, we also used a furnace with multi-crucibles, in which as many as six crystal boules could be grown simultaneously in one growth cycle.

The platinum crucible used in crystal growth was 25 $40 \mathrm{~mm}$ in diameter and $200 \sim 250 \mathrm{~mm}$ in length with a seed well of $10 \mathrm{~mm}$ in diameter at the conical bottom to hold the seed crystal. The crucibles could be used only once for one growth cycle because they must be cut in order to take out the grown crystals. In order to obtain the seed crystal, the initial tries of the growth were done by spontaneous nucleation from the seed wells. Transparent

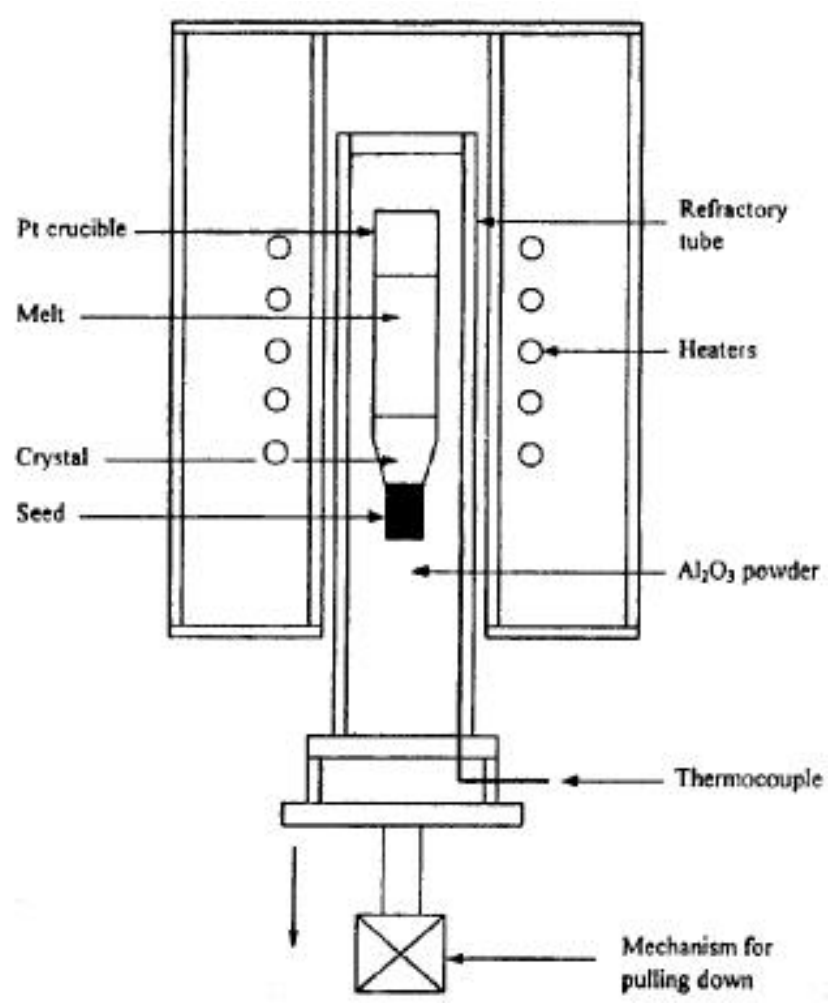

Figure 1. Scheme of vertical Bridgman furnace. single crystals with size of $\Phi 10 \times 40 \sim 60 \mathrm{~mm}$ were chosen as the seeds after the crystals were oriented, cut and ground. The seeds were put in the seed wells, then the feed materials were filled in the cylinder of crucibles. The assembled crucible was sealed in order to prevent the volatilization of the melt during crystal growth. The crucible was installed in a refractory tube filled with $\mathrm{Al}_{2} \mathrm{O}_{3}$ powder to isolate it from external temperature fluctuations. In order to detect the axial temperatures along the crucible, the crucible was fitted with two $\mathrm{Pt}-\mathrm{Pt} / \mathrm{Rh} 10 \%$ thermocouples. Figure 2 is the axial temperature distribution measured by the thermocouple near the crucible.

After the crucible had been placed in the furnace, it was heated to the controlled temperature at the rate of $100^{\circ} \mathrm{C} / \mathrm{h}$. Seeding process was performed by adjusting the crucible to such a position that only the seed top was melted. The feed material and the seed top were kept at the melting state for several hours so that a stable solidliquid interface can be established on the top region of the seed. The temperature gradient across solid-liquid (s-1) interface was around $20 \sim 40^{\circ} \mathrm{C} / \mathrm{cm}$. Growth process was driven by lowering the crucible at a rate of $0.6 \sim$ $1.4 \mathrm{~mm} / \mathrm{h}$. To prevent cracking resulting from thermal stress in the crystals, as grown boule was annealed in the lower zone during growth. After the growth had finished, the furnace was cooled to room temperature at a rate of $20 \sim 50^{\circ} \mathrm{C} / \mathrm{h}$. The crucible was stripped after taking it out of the refractory tube and as-grown crystal was obtained. In order to eliminate the residual stress inside the crystals, they were annealed further in a resistant furnace. The crystals were heated to $800 \sim 900^{\circ} \mathrm{C}$ at the rate of

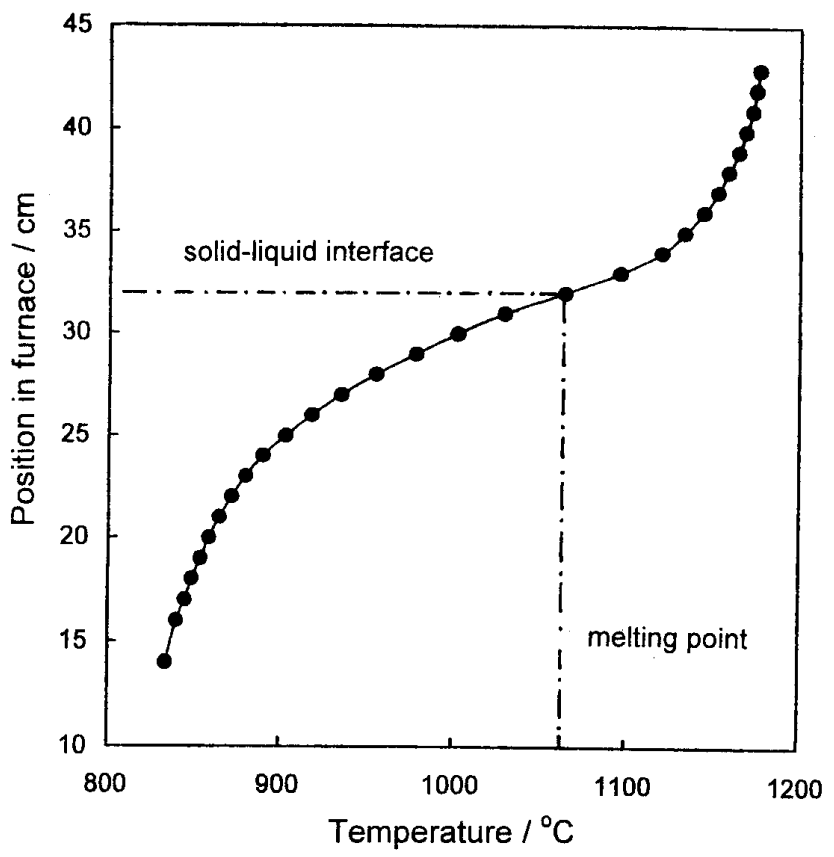

Figure 2. Axial temperature profile in furnace. 
$50^{\circ} \mathrm{C} / \mathrm{h}$, held at that temperature for $20 \mathrm{~h}$ and finally cooled to room temperature at the rate of $30^{\circ} \mathrm{C} / \mathrm{h}$.

$\mathrm{X}$-ray diffraction analysis of grown crystals was performed with a diffractometer, using monochromatic $\mathrm{CuK}_{\alpha}$ radiation with a working voltage of $40 \mathrm{kV}$ and current of $100 \mathrm{~mA}$. The sample was analysed by DTA/TG using a Seiko EXSTAR 6300 thermal analyser calibrated by $\mathrm{Al}_{2} \mathrm{O}_{3}$. A $10 \mathrm{mg}$ sample was tested at the heating and cooling rates of $10^{\circ} \mathrm{C} / \mathrm{min}$. X-ray fluorescence analysis was used to determine the distribution of $\mathrm{Pb}$ and Mo concentration along the growth axis. The crystallinity of the crystal is investigated by the doubled-crystal $\mathrm{X}$-ray rocking curve analysis for the (101) reflection. The double-crystal Xray rocking curve was measured by a Philips materials research diffractometer equipped with a four-crystal (220) Ge Bartels-tape monochromator. The transmission spectra of the samples with $40 \mathrm{~mm}$ in thickness were measured with a SHIMADZU UV-2501 (PC)S spectrometer in the range $300-800 \mathrm{~nm}$ at room temperature.

\section{Results and discussion}

\subsection{Composition of feed materials}

The feed material with appropriate composition is very important for growing high quality PMO crystals. In order to investigate the effect of melt composition, the feed materials with different compositions were used in the experiments. The composition of the feed materials was chosen to be (i) stoichiometric, (ii) $1.0 \mathrm{~mol} \%$ excess $\mathrm{PbO}$ and (iii) $1.0 \mathrm{~mol} \%$ excess $\mathrm{MoO}_{3}$. An interesting phenomenon was noted from the appearance of as-grown crystals. If the feed material was prepared with strict stoichiometric composition, all the melt was converted into transparent single crystals. However, using the feed materials with the nonstoichiometric composition, there was a pale yellow segregation on the surface and on the top of the crystals. The segregation was first formed a bit inside the boule near the shoulder and then propagated to the surface along the body of the boule as the growth proceeded. Although the boules were coated with pale yellow segregation, the internal medium was very clear showing good optical transparency.

X-ray diffraction analysis has been applied to determine the phase of segregation. Figures 3 and 4 show the $\mathrm{X}$-ray diffraction patterns of the pure crystal and the segregation collected from the boules, respectively. The crystal grown from the stoichiometric melt was confirmed to be $\mathrm{PbMoO}_{4}$ without other phases, while the segregation was verified to contain $\mathrm{Pb}_{2} \mathrm{MoO}_{5}$ or $\mathrm{MoO}_{3}$ phase in addition to $\mathrm{PbMoO}_{4}$ for the melt composition with excess $\mathrm{PbO}$ or $\mathrm{MoO}_{3}$. For the case of excess $\mathrm{PbO}$, the pattern presents two sets of diffraction peaks corresponding to $\mathrm{Pb}_{2} \mathrm{MoO}_{5}$ and $\mathrm{PbMoO}_{4}$ phase, respectively, which indicates that the segregation contains a large quantity of $\mathrm{Pb}_{2} \mathrm{MoO}_{5}$ in addi- tion to $\mathrm{PbMoO}_{4}$. For the case of excess $\mathrm{MoO}_{3}$, the pattern shows stronger peaks corresponding to a large quantity of $\mathrm{PbMoO}_{4}$ and weaker peaks corresponding to a small quantity of $\mathrm{MoO}_{3}$. As the compound synthesized from the solution reaction was used as feed material, the grown crystal was colourless, transparent without any segregation on the top or on the surface. The results indicate that the feed material with strict stoichiometric composition is desirable for the Bridgman growth of PMO crystals.

The composition of melts should be kept stable in order to grow high quality crystals. To investigate the volatilization of the melt in the process, the crystal was tested by DTA/TG analysis in air. The DTA and TG curves are present in figure 5. The DTA curve shows that the crystal is melted congruently at $1065^{\circ} \mathrm{C}$. It is noted that a distinct weight loss occurs above the melting point. There is about 19 wt $\%$ weight loss on the TG curve from $1040-1270^{\circ} \mathrm{C}$. The composition of PMO melts changes continuously in the Czochralski process because of different volatility of $\mathrm{PbO}$ and $\mathrm{MoO}_{3}$ under normal atmosphere. Lin (1978) has verified that the volatility of $\mathrm{MoO}_{3}$ is more than that of $\mathrm{PbO}$ in the Czochralski process. It is usually difficult to compensate the weight loss precisely to avoid the composition deviation of the melts. In the modified Bridgman process, the volatilization could be avoided effectively by sealing the crucibles. No evident weight losses occurred during the growth because the vapour could be enclosed in the sealed crucibles and the composition of the melts is kept constant during growth. The modified Bridgman process shows some advantage at this point over the conventional Czochralski method as reported in the previous literatures.

\subsection{Growth rate and temperature distribution}

The growth rate of PMO crystal is allowed to be fast relatively because the viscosity of the melt is not very high.

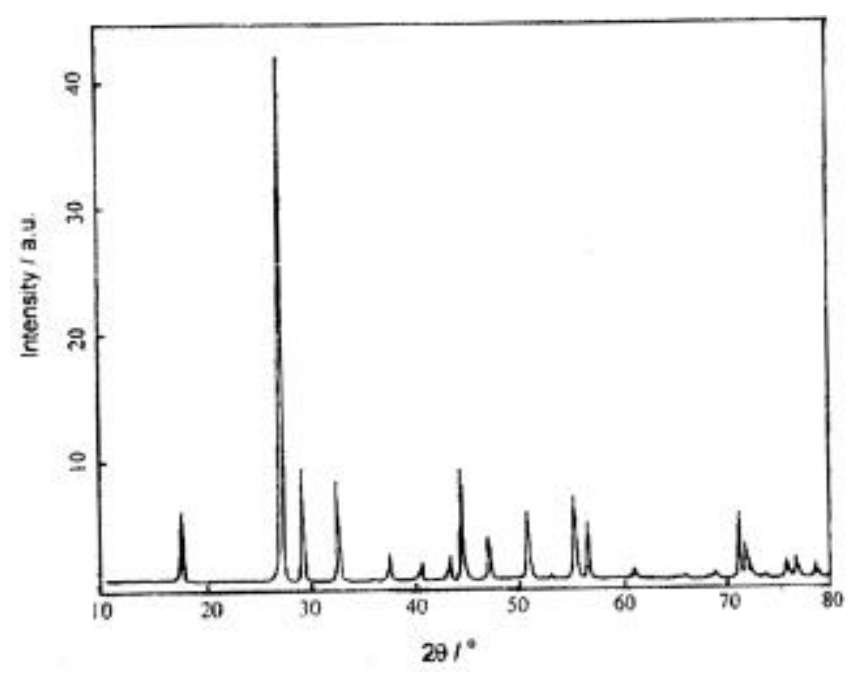

Figure 3. X-ray diffraction pattern of $\mathrm{PbMoO}_{4}$ single crystal. 
In the Czochralski method, high quality crystals can be grown by the growth rate of $1 \sim 3 \mathrm{~mm} / \mathrm{h}$ (He et al 1980; Lim et al 1996). Because there is no forced convection in the melt during Bridgman growth, a slower growth rate should be used to grow the crystals with similar quality. For the stoichiometric composition of the feed materials, the crystals were grown at different rates of $0 \cdot 6,0 \cdot 8,1 \cdot 0$, $1.2,1.4 \mathrm{~mm} / \mathrm{h}$. The grown crystals were cut perpendicular to the growth direction so that the quality of the crystals could be observed. The crystals were observed to be clear inside without any macro-defects as the growth rate was controlled in the range of $0.6 \sim 1.2 \mathrm{~mm} / \mathrm{h}$. However, as the growth was conducted at a rate more than $1.2 \mathrm{~mm} / \mathrm{h}$, the crystal quality becomes deteriorated. So the growth rate in the range of $0.6 \sim 1.2 \mathrm{~mm} / \mathrm{h}$ is desirable to grow good quality PMO crystals. The larger diameter crystals should be grown by even slower growth rate.

The solid-liquid interface, where the crystallization takes place, is another important factor for growing high
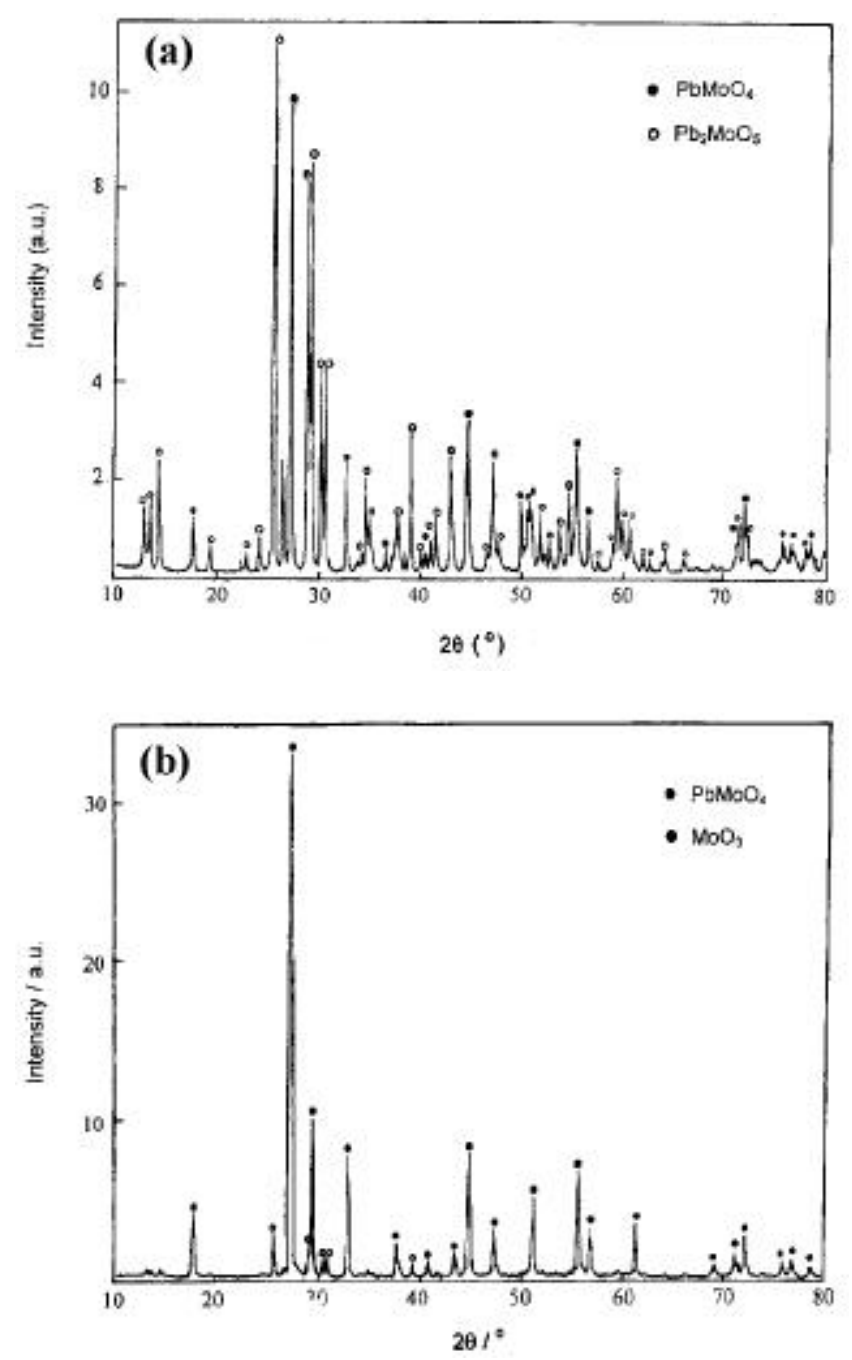

Figure 4. X-ray diffraction pattern of segregation phase for the crystal grown with (a) excess $\mathrm{PbO}$ and (b) excess $\mathrm{MoO}_{3}$. quality crystals. The temperature gradient of solid-liquid interface in the Bridgman furnace is usually lower than that in Czochralski growth, therefore, the cracking is easier to be avoided during Bridgman growth. A moderate temperature gradient of solid-liquid interface is essential to the Bridgman crystal growth. If the temperature gradient is too low, the growth rate is less than the lowering rate of crucible and the solid-liquid boundary formed concave towards the melt. Under such circumstances, the crystals usually contain more scattering particles as the impurities cannot be expelled easily during growth. On the contrary, if the temperature is too high, the growth rate is more than the lowering rate of crucible and the solid-liquid boundary formed convex towards the melt. As a result, the cracking as well as the cloud layer tends to form easily and the transparency of crystals is degraded. In our process, the temperature gradient of solidliquid interface is controlled in the range of $20 \sim 40^{\circ} \mathrm{C}$. The solid-liquid interface is kept flat and the quality of crystals is improved.

The seeding operation is a key process to grow largesize PMO crystals in the vertical Bridgman method. In our process, as the solid-liquid boundary could not be observed directly, the seeding operation was carried out according to the temperature measured by a thermocouple $\left(T_{\mathrm{s}}\right)$. The thermocouple was installed to be on level with the seed top in a refractory tube. The seeding operation could be performed by adjusting the crucible to such a position that the temperature $\left(T_{\mathrm{s}}\right)$ was just a bit more than the melting point $\left(1065^{\circ} \mathrm{C}\right)$. The feed material and the seed top must be kept for enough time at the melting state so that a stable solid-liquid interface was established on top region of the seed. However, the seed operation could not always be carried out successfully because of the temperature deviation measured by the thermocouple. If the temperature was controlled to be too low or too high, the seed could not be melted with the feed material or the seed might be melted out. So the seed operation must be performed carefully with an

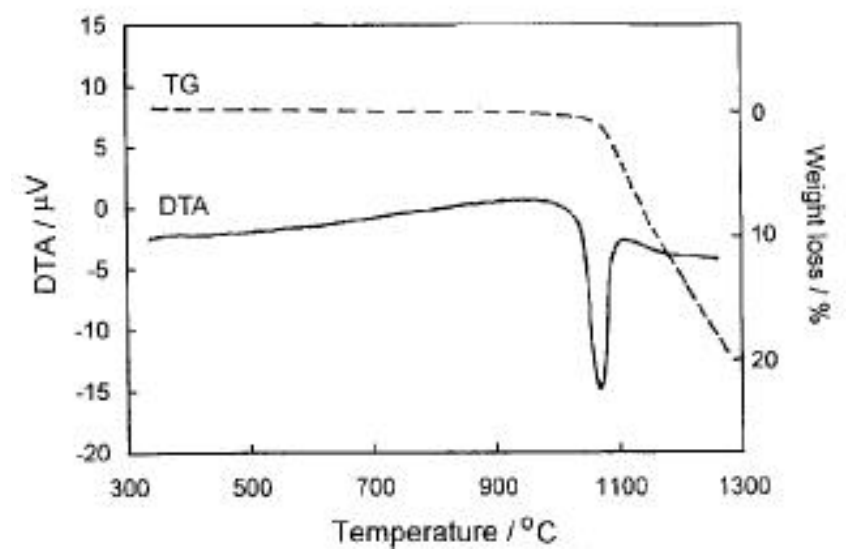

Figure 5. DTA/TG curves of $\mathrm{PbMoO}_{4}$ crystal. 
appropriate seeding temperature, which could be obtained from experience by repeated experiments. In addition, a moderate temperature gradient of solid-liquid interface was necessary for performing the seeding operation successfully. Under smaller temperature gradient, the seeding operation becomes more difficult although the cracking can be avoided easily, while larger temperature gradient is convenient for the seeding but tends to bring about the cracking.

\subsection{PMO crystal grown by Bridgman method}

PMO single crystals have been grown successfully by the described process. All the melt was converted into crys-

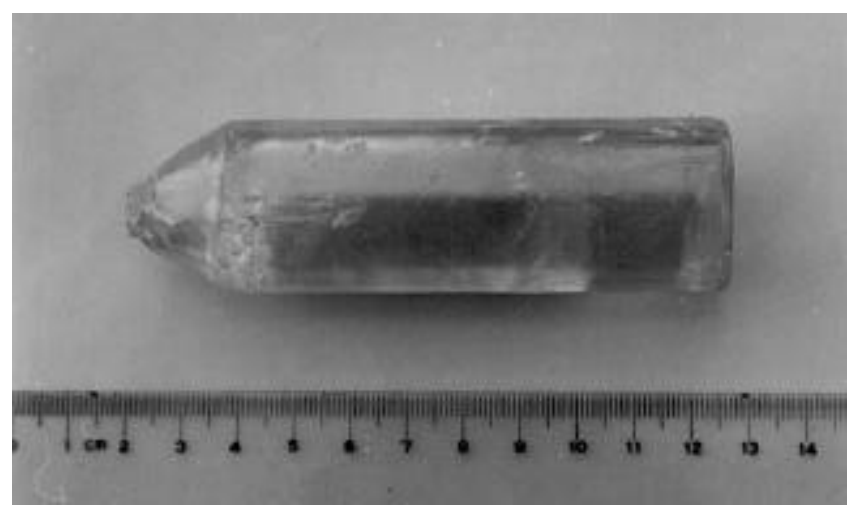

Figure 6. $\mathrm{PbMoO}_{4}$ crystal grown by modified Bridgman method.

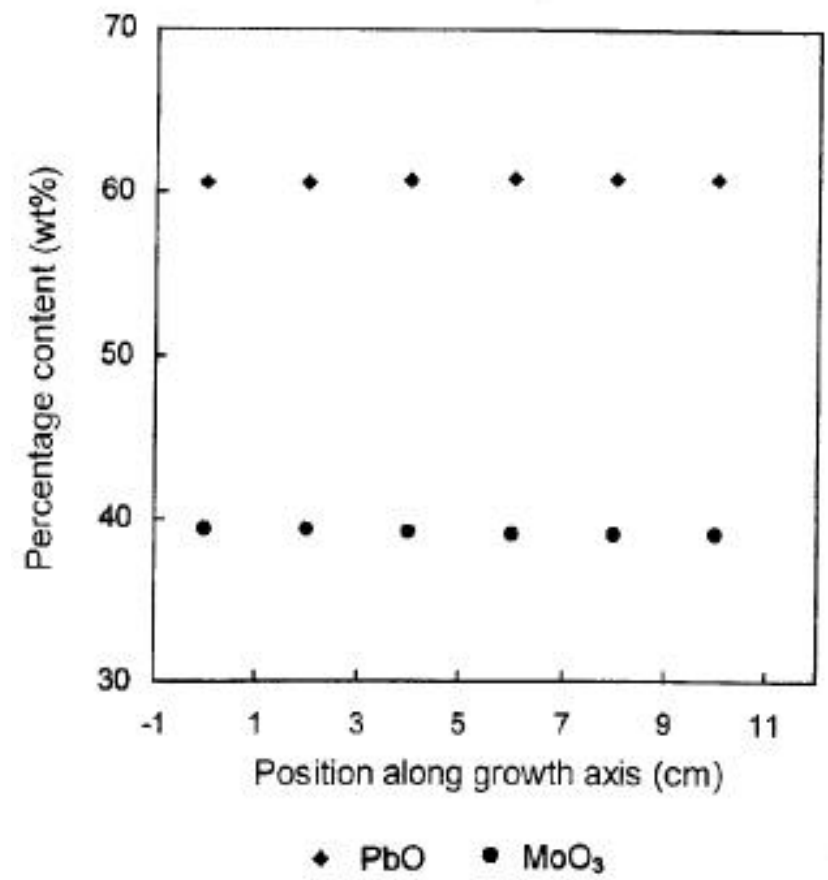

Figure 7. The composition distribution of $\mathrm{PbMoO}_{4}$ crystal along the growth axis. tals without any remains in the crucibles. As-grown crystals take the shape of the crucibles, so the crystals with different shapes such as cylinder or block can be grown arbitrarily. Figure 6 shows an as-grown crystal, which is colourless and transparent along $\langle 100\rangle$ orientation with the size $30 \mathrm{~mm}$ in diameter by $100 \mathrm{~mm}$ in length. The crystal was examined to be free from scattering centres by a He-Ne laser. Although the crystals have been annealed simultaneously during growth in the low-temperature zone, further annealing treatment is necessary for the crystals to be fabricated into components without producing any cracks.

To investigate the distribution of $\mathrm{Pb}$ and Mo concentration along the growth direction, chemical composition of the grown crystal was measured by X-ray fluorescence analysis. Six samples were taken every $2 \mathrm{~cm}$ length from the bottom to the top of the crystal boule. Figure 7 presents the percentage contents of $\mathrm{PbO}$ and $\mathrm{MoO}_{3}$ in the crystal as function of positions. The result shows that the compositions are almost homogeneous along the growth axis. The crystallinity of the grown crystal is investigated by the double-crystal X-ray rocking curve analysis. Figure 8 shows the $\mathrm{X}$-ray rocking curve, which exhibits a FWHM value of $\sim 40$ arc sec. The result shows that the grown crystal has a desirable crystallinity. We are trying to grow the crystals with even higher quality by improving the growth conditions.

To measure the optical transmittance of crystals, the samples were fabricated from the crystal grown with the stoichiometric feed materials. Figure 9 presents the transmission spectrum of crystal, in which the absorption edge is located around $380 \mathrm{~nm}$ and the transmittance above $500 \mathrm{~nm}$ is about $70 \%$. For the samples obtained from different parts of the crystals, almost no difference in trans-

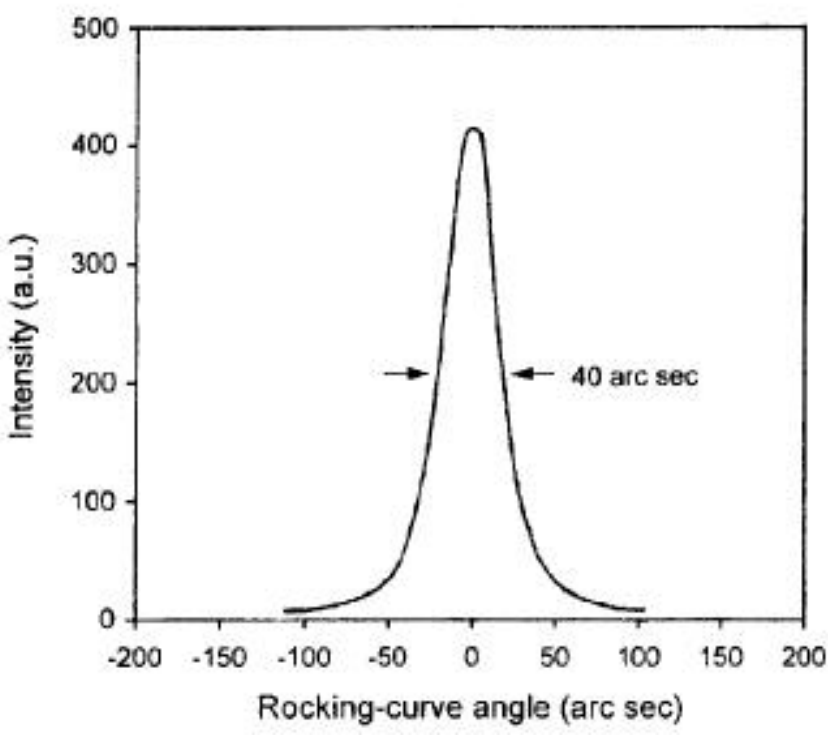

Figure 8. X-ray rocking curve of $\mathrm{PbMoO}_{4}$ crystal. 


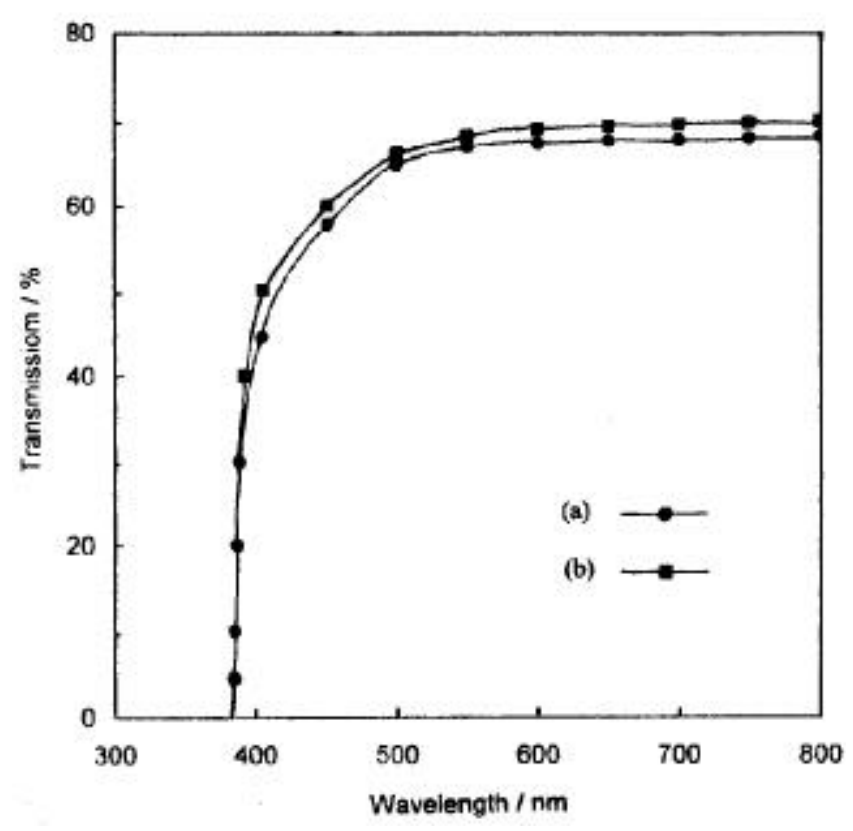

Figure 9. Transmission spectrum of $\mathrm{PbMoO}_{4}$ crystals grown with the feed material synthesized by (a) solid state reaction or (b) solution reaction.

mission is recognized. However, for the crystal grown with the material synthesized from the solution, its optical transmittance is somewhat higher. The result indicates that this kind of material is more suitable for growing high quality PMO crystals because of its exact stoichiometry.

Now the authors are trying to grow 2 inches diameter PMO crystals by the modified Bridgman method with multi-crucibles. In our process, as many as six crystal boules can be grown in one furnace simultaneously. Additionally, using block shaped crucible, we can also grow the crystals with block shape, which is more convenient for device fabrication with higher material utilization ratio. Owing to the advantages mentioned above, the present Bridgman process is promising for mass production of PMO crystals with lower cost.

\section{Conclusions}

Large size PMO crystals have been grown successfully by the modified Bridgman process. The feed material with strict stoichiometric composition is suitable for the Bridgman growth of PMO crystals. The continuous composition change of the melts during growth can be avoided because the volatilization of melts is limited by sealed platinum crucibles. The growth parameters are optimized as the growth rate of $<1.2 \mathrm{~mm} / \mathrm{h}$ coordinated with the temperature gradient of $20 \sim 40^{\circ} \mathrm{C} / \mathrm{cm}$ across the solid-liquid interface under the furnace temperature of $1140 \sim 1200^{\circ} \mathrm{C}$. The characterizations indicate that the grown crystals have good compositional homogeneity, desirable crystallinity and with high optical uniformity. This work demonstrates that the modified Bridgman process is practical for mass growth of large-size PMO single crystals.

\section{Acknowledgements}

This work is supported by the Project of Science and Technology in Ningbo City under Grant No. 2002B10024 and the Doctor Science Project of Ningbo City under Grant No. 01J20300-14. The authors would like to thank Mr Pingfu Shen, Shanghai Institute of Ceramics, for his helpful discussion.

\section{References}

Bonner W A and Zydzik G J 1970 J. Crystal Growth 765

He Chongfan, Lin Youyi, Su Weitang and Shen Bingfu $1980 \mathrm{~J}$. Chinese Ceram. Soc. 9285 (in Chinese)

Jaeger F M and Germs H C 1921 Anorg Z. Allgerm. Chem. 119145

Lim L C, Tan L K and Zeng H C 1996 J. Crystal Growth 167686

Lin Youyi 1978 Symposium on annual conference of Chinese Ceramics Society, Shanghai, China, p. 60 (in Chinese)

Pinnow D A 1969 Appl. Phys. Lett. 1583

Senguttuvan N, Babu S I and Dhanasekaran R 1997a Mater. Chem. \& Phys. 49120

Senguttuvan N, Babu S I and Subramanian C 1997b Mater. Sci. \& Eng. B47 269

Takano S 1974 J. Crystal Growth 24/25 437

Zeng H C 1997 J. Crystal Growth 171136 